\title{
O TEMPO E O ESPAÇO DO "EU" MENINO: A INFÂNCIA COMO TERRITÓRIO DE CRIAÇÃO NA OBRA DE LOBO ANTUNES LEITURA
}

\author{
THE TIME AND SPACE OF THE BOY "I": CHILDHOOD AS A \\ TERRITORY OF CREATION IN THE WORKS OF LOBO ANTUNES
}

Maria Elvira Brito Campos*

\begin{abstract}
RESUMO
O presente ensaio trata de questões inerentes à construção do tempo e da memória nas crônicas do escritor português contemporâneo António Lobo Antunes. É sabido que, epistemologicamente, esse gênero literário é constituído a partir da gênese do seu nome (crônica - chronos/kairós) e, desse viés temático, este trabalho busca mostrar como a memória e o tempo permeiam o vivido e o imaginado, como o encontro imagético entre avô e neto, num futuro construído por memórias.
\end{abstract}

PALAVRAS-CHAVE: Crônica. Tempo. Memória

\begin{abstract}
This essay discusses the issues inherent to the construction of time and memory in the chronicles by the contemponeous Portuguese writer António Lobo Antunes. Epistemologically, this literary genre is known as what constitutes the genesis of its name (chronicle - chronos/kairós). It is based on this thematic bias that the present work strives to show how memory and time permeate what is real and what is imagined, like the imaginary encounter of a grandparent and a grandchild in a future built by memories.
\end{abstract}

KAYWORDS: Chronicle. Time. Memory

O passado é a coisa mais imprevisível do mundo, não para de se transformar.

(ANTUNES)

Nos cinco livros de crônicas de Lobo Antunes, publicados até 2014, encontramos sempre algum que retrata o menino Antoninho no bairro de Benfica, em Lisboa (onde sua família morou por toda a vida), ou na casa do avô, na Freguesia de Nelas. A escritora e pesquisadora portuguesa, Maria Alzira Seixo, em entrevista concedida a Maria Luísa Blanco, fala sobre a importância das lembranças nesse período de vida de Lobo Antunes: "se o primeiro olhar sobre as coisas configura a visão do mundo, a infância é sem dúvida o território onde se gera essa cosmovisão". E conclui: "nos seus

\footnotetext{
* Professora Associada da Universidade Federal do Piauí (UFPI). Doutoraem Estudos Comparados de Literatura de Língua Portuguesa pela Universidade de São Paulo. Email: mebcampos@hotmail.com
} 
livros nas suas crônicas, encontram-se, como folgachos, essas primeiras impressões vitais que marcam a singular estética do escritor" (BLANCO, 2002, p. 23).

Recuperar as lembranças dessa parte da vida é uma atividade que certamente movimenta e “desdobra uma série de raciocínios abstratos”, como nos diz Bergson (1999, p. 6), acerca da seleção das imagens para a representação, pois o passado é contínuo, e quando mergulhamos nele não sabemos que lembrança virá à tona. Inegável a dificuldade de expressão desse tema na obra Matéria e Memória (1999), mas é inegável também o reconhecimento da contribuição de Bergson para a compreensão dessa questão. Embora pareça contraditório, a dificuldade nos permite esgotar as nossas inferências, ao trazê-las à luz para o entendimento de obras diversas. Por isso, parece-nos interessante o retomar de uma das questões mais evidentes em Bergson sobre o desencadear da memória:

Se a percepção exterior, com efeito, provoca de nossa parte movimentos que a
desenham em linhas gerais, nossa memória dirige à percepção recebida as antigas
imagens que se assemelham a ela e cujo esboço já foi traçado por nossos
movimentos. Ela cria assim pela segunda vez a percepção presente, ou melhor,
duplica essa percepção ao lhe devolver, seja sua própria imagem, seja uma
imagem-lembrança do mesmo tipo. Se a imagem retida ou rememorada não chega
a cobrir todos os detalhes da imagem percebida, um apelo é lançado às regiões
mais profundas e afastadas da memória, até que outros detalhes conhecidos
venham a se projetar sobre aqueles que se ignoram. E a operação pode prosseguir
indefinidamente, a memória fortalecendo e enriquecendo a percepção, a qual, por
sua vez, atrai para si um número crescente de lembranças complementares
(BERGSON, 1999, p. 114-115).

Se a matéria, para Bergson (e por que não, para nós?), é um conjunto de imagens, e se imagem é aquilo que representa algo, logo, segundo ele, para "o senso comum, o objeto existe nele mesmo e, por outro lado, o objeto é a imagem dele tal como a percebemos: é uma imagem, mas uma imagem que existe em si”. Entretanto, alocada na consciência, temos a lembrança, da qual o mesmo Bergson observa:

[...] a lembrança - conforme procuraremos mostrar na presente obra - representa precisamente o ponto de interseção entre o espírito e a matéria. Mas pouco importa a razão: ninguém contestará, creio eu, que no conjunto de fatos capazes de lançar alguma luz sobre a relação psicofisiológica, os que concernem à memória, seja no estado normal, seja no estado patológico, ocupam um lugar privilegiado (BERGSON, 1999, p. 9).

Nesse artigo, as questões relativas a tempo e memória recaem sobre o menino "Antoninho", aquele que tanto espreita a vida, que tanto reflete, que tanto se inquieta. Em Livro de Crónica, de Lobo Antunes, temos algumas questões filosóficas a cotejar, dentre elas, a recuperação das lembranças por meio do desdobramento de uma série de raciocínios abstratos, como referiu Bergson, e o desdobramento do sujeito, pois no espaço entre os dois (autor e narrador) se aloja a ficção, parafraseando Jakobson (apud LAURENT, 1982, p. 98). A partir dessa tensão de preparo para que se acione o gatilho da memória, sabemos que muito aqui há de ser autobiográfico, mas que, ao se repartir, o escritor se agarra à recordação e a refaz. 
Como exemplo, temos a crônica "O surdo", que assim tem início:

O pai da minha mãe não era um homem, era um centauro, metade avô e metade aparelho de ouvir. No que respeita à metade avô que morreu quando eu tinha 12 anos, lembro-me do cabelo branco na varanda de Nelas, casaco de linho, do Diário de Notícias que chegava no comboio do meio-dia lido no sofá da sala, do silêncio que o cercava sempre apesar da inquietação dos castanheiros ao redor da casa, e do Bryllcream

(não sei se é assim que se escreve)

que lhe roubava às escondidas para me parecer com Neil Sedaka

$[\ldots]$

A metade aparelho para ouvir, porque ainda não tinham inventado esses feijões de plástico de meter na orelha, consistia numa espécie de walkman cuja caixinha das cassetes se enfiava no bolso do peito ligada aos auscultadores por um emaranhado de fios. O meu avô morreu, o aparelho ficou, e recordo-me de um dia abrir uma gaveta da cómoda, retirar dela a fracção do meu avô, colocar aquilo tudo como um padre se paramenta para a missa e de a minha cabeça se transformar numa gruta de cimento, idêntica a uma garagem à noite, onde o mínimo eco ganhava as proporções terríveis de uma explosão atómica [...]

A surdez passou do meu avô para a minha mãe e da minha mãe para mim e compreendi por os descobrir em mim próprio, o sorriso e os acenos de cabeça deles sempre que alguém lhes falava (ANTUNES, 1998, p. 83 - 85).

O círculo da vida é aqui guardado no ouvido, caixa de ressonância que, em queda de funcionamento, faz-se orientar apenas pela imagem. E a imagem, assim como o som, reconstitui o tempo, e se repete. O menino se reencontra com o avô, carregando o legado também da mãe. Ele dá continuidade à duração de uma família, mesmo saltando os espaços em branco, impossíveis de serem preenchidos na totalidade. Então, entra o escritor que reconta, revê e restaura.

O processo de individuação do menino, que nos traz à cena o avô, é possibilitado pelo deslocamento do sujeito nos meandros da memória. A mesma história poderia ser contada de outra forma, por meio do olhar médico, psiquiátrico, mas foi a poesia que nos transportou para o enlevo do legado do menino que carrega a máquina, agora minimizada ao tamanho de um feijão, mas que o distancia do mundo: "compreendi por os descobrir em mim próprio, o sorriso e os acenos de cabeça deles sempre que alguém lhes falava", quando quer apenas imergir em si.

Da mesma forma, o tempo que a princípio nos traz o menino revela o adulto, e está inexoravelmente dentro dele o sentimento, o prazer em descrever o vivido. Se há algo que podemos perceber nessas crônicas, é que o lirismo dilui o rancor. Há sempre um vigor e uma alegria, mesmo quando a memória percorre o trilho dos desencantos: há sempre um poema a sustentar o relato.

Resisto ao feijão: desde que sou surdo sorrio que me farto e concordo a torto e a direito, com uma benevolência inalterável e tocante. Julgam-me feliz: sou mouco. Cuidam-me franciscano: sou apenas surdo. E só desejo que não me aconteça, como ao pai da minha mãe, que um amigo me puxe pelo braço numa confidência comprida para perguntar no fim

- O que achas tu António?

ao que ele, que nada ouvira, respondeu para ser agradável ao outro

- Isso é de uma estupidez

e nunca se recompôs do facto de um amigo, sem que o meu avô jamais descobrisse o motivo, ter cortado relações com ele.

Se tal me suceder compro o feijão da D. Ilda Capinha e como nas experiências de Biologia do liceu fico à espera que ele germine para dentro da 
orelha em folhazitas de sons. Ou retiro da gaveta da cómoda a tremenda ferramenta acústica, compro um casaco de linho, regresso a Nelas, enfio o dedo no pote de Bryllcream (que serve ao mesmo tempo para empastar o cabelo e para barrar o pão) e trago do comboio, ao meio-dia, as notícias de 1950.

(ANTUNES, 1998, p. 83-85)

Do menino ao adulto, somos necessariamente levados ao que se observa sobre o pensamento, como gatilho acionado para uma lembrança não determinada por datas ou comemorações, ao clique espontâneo que surge e que nos faz passear pelo tempo, exemplificado nos excertos da crônica apresentada. Do pensamento, entretanto, a partir de estímulos visuais ou sensoriais, dos quais não temos controle, ele nos traz recordações imprevisíveis. Transformar essas recordações em imagens etéreas, fugazes, exatamente por serem recordações, diferentemente da imagem cinematográfica, que reproduz fielmente o fato, é o que consegue executar a literatura. A imagem fílmica pode, também, incorporar certos traços de impressionismo, como no caso do cinema neorrealista ou da nouvelle vague, dos anos 60 do século XX. De acordo com a direção de cena, pode transformar o imaginado numa cena remota e esfumada, mas o que vemos com mais intensidade é a reprodução do vivido numa reprise, tal qual a cena que deu origem a esta.

Captando as ideias em movimento, Lobo Antunes consegue recriar ou criar imagens que nos conduzem ao evento citado, prenhe de emoção. Não é à toa que o passado retorna ante a afirmação “e trago do comboio, ao meio-dia, as notícias de 1950”. A data, embora meados do século XX, ainda está na memória do menino, que por sua vez está guardado no adulto. E a caixa de audição reverbera os sons do avô com quem conviveu até os seus 12 anos. Pensando nisso, recordamos passagens que descrevem cenas da sua infância, e de como a poesia faz parte da construção do seu olhar e, a seu modo, de ouvir o mundo. Como na crônica "O osso" e em "Antoninho cravo roxo", ambas do Terceiro livro de crónicas:

O meu avô não acabava de ler a história, em vários volumes, da segunda guerra mundial, com fotografias de aviões e de mortos. Aos doze anos, no ano em que ele morreu, decidi ser escritor. As minhas influências: Salgari, Flash Gordon e o Almanaque Bertrand, cheio de sonetos entusiastas (ANTUNES, 2005, p. 44).

Nunca ninguém me chamou assim a não ser ela. Dizia

Antoninho cravo roxo

Dizia

Quem me dera a sua idade

e no entanto casou com outro. Também mais novo do que ela, um ou dois anos mais novo do que ela. Não percebo porque o preferiu a mim, que tinha menos vinte e um anos, estava a acabar a instrução primária, considerava-me um alho no hóquei e ainda por cima era da família. O problema não consistia em eu querer casar com ela: consistia em não querer que ela casasse com ninguém, que ficasse sempre ali, em casa dos meus avós a dar lições de piano. [...]

Mostrava as redacções, com a classificação de Muito Medíocre, a encarnado grande, à que me chamava Antoninho cravo roxo, ela lia-as, relia-as, seguia-se silêncio igual ao do professor de Português,

Em lugar do

-Sua besta

vinha uma frase a medo

-Eu acho que o menino ainda acaba escritor 
e eu, um futuro rei de hóquei, a olhar para ela indignado. [...]

O menino acabou escritor (ANTUNES, 2005, p. 115)

Os excertos exemplificam o modo como as crônicas antunianas evocam as memórias da infância por meio do olhar do menino que observa o adulto. As imagens etéreas e não reproduzidas fielmente, como acontece, em flashbacks ou reprises de cenas, nos filmes. São trazidas ao autor narrador, por odores, gestos e palavras como expressa o menino Antoninho, mesmo narrado pelo António adulto. Esse gênero literário não é simplesmente uma mistura da poesia no texto, mas a condensação do lirismo expresso de uma forma poética não tradicional, liberta do verso, da rima, da estrofe e espalhada por toda a página, como prosa poética.

Se na crônica lemos “e trago do comboio, ao meio-dia, as notícias de 1950” (ANTUNES, 1998, p. 83-85), inevitavelmente alcançamos essa sensação. E esse enlevo que nos conduz ao passado por meio de uma frase apresenta metaforicamente o tempo como transporte materializado em comboio, para o que ficou lá atrás, numa cronologia ilustrada pelo jornal de 1950. Nessa frase, temos, novamente, o menino e seu avô a se aproximarem pelo tempo e pelo sentimento, como nos antecipou Baudelaire, "o milagre de uma prosa poética, musical, sem ritmo e sem rima, flexível e desencontrada o bastante para adaptar-se aos movimentos líricos da alma, às ondulações do devaneio, aos sobressaltos da consciência” (BAUDELAIRE, 1996, p. 23-25). Esse encontro se faz possível por meio de recursos digressivos, como o da analepse e prolepse, que propiciam a visualização do flashback, da viagem ao passado. Paula Mourão (2011), em consideração às crônicas publicadas na revista Visão, esclarece:

O sujeito que escreve interroga-se não só sobre o eu (desdobrado nos retratos ou nos espelhos em $t u$ ou mesmo em terceira pessoa), como sobre a sua origem, em dois sentidos essenciais. Assim, por um lado parte em demanda do seu nome (António, Lobo Antunes, António Lobo Antunes), [...] e a aqui acrescentamos também o Antoninho [...] - ao encontro de uma linhagem que conduz ao passado infantil, aos avós e aos pais; mas por outro lado essa busca acarreta a presentificação das casas e de outros lugares que contrastam com o presente, muitas vezes desolado. (MOURÃO, 2011, p. 25-26. Grifo e inferência nossa)

Como bem nos diz Bergson (2011), tempo é duração, é a experiência da continuidade1, o que Lobo Antunes referenda: “O tempo é modulado pela duração” (MOURÃO, 2011, p 41). Entre uma passagem e outra dos hiatos da vida, da sequência não linear, há instantes que funcionam como fotografias e que nos fazem remontar à passagem. Na consciência, temos dados que se alternam, diferentemente do que nos apresenta o mundo exterior. Como disse Lobo Antunes na citada entrevista à Revista Visão "O passado é a coisa mais imprevisível do mundo, não para de se transformar." (ANTUNES, 2013, p. 112/122).

Como o próprio autor afirma, essa assertiva é de George Orwell, mas que, a nós, ilustra em muito essa compreensão de como retratar alguns fatos ocorridos em detrimento de outros, ou de

\footnotetext{
${ }^{1}$ Bergson, em Ensaio sobre os dados imediatos da consciência, 2011, afirma: "Sem dúvida, é possível perceber no tempo, e apenas no tempo, uma sucessão pura e simples, mas não uma adição, isto é, uma sucessão que viesse a dar uma soma. (2011, p. 66) [...] Que é a duração dentro de nós? Uma multiplicidade qualitativa, sem semelhança com o número” (2011, p. 170)
} 
como alteramos o fato ocorrido em detrimento da distância que dele nos afasta, ou do nosso estado de espírito ao reconsiderar a lembrança. Dentre os "movimentos líricos da alma" temos a visão do menino que vê o mundo de baixo para cima, observa os ínfimos detalhes, que a ele parecem determinantes na gigantesca memória. Na crônica “As pessoas crescidas”, lemos:

\begin{abstract}
As pessoas crescidas fui-as conhecendo de baixo para cima à medida que a minha idade ia subindo em centímetros, marcados na parede pelo lápis da minha mãe. Primeiro eram sapatos, por vezes descobertos sob a cama, enormes, sem pé dentro, e logo calçados por mim para caminhar pela casa, erguendo as pernas como um escafandrista, num estrondo imenso de solas. Depois tomei conhecimento dos joelhos cobertos de fazenda ou de meias de vidro, formando ao redor da mesa debaixo da qual eu gatinhava uma paliçada que me impedia de fugir. A seguir vieram as barrigas de onde a voz, a tosse e a autoridade saíam apesar do esforço de suspensórios e de cintos (ANTUNES, 1998, p. 59-61).
\end{abstract}

Sapatos, joelhos, barrigas. O narrador, ou o autor, como já vimos, nos apresenta o crescimento físico e psicológico da personagem a partir da sequência das partes do corpo humano, e também nos conduz a uma visão fragmentada de como a personagem vê o mundo, em consequência do seu crescimento. E o sapato, o joelho e a barriga se tornam elementos poéticos. Novamente o tempo carregando a poesia, como deusas sob liteiras. E como nos diz María Luisa Blanco (2002, p. 23),

Se o primeiro olhar sobre as coisas configura a visão do mundo, a infância é sem dúvida o território onde se gera essa cosmovisão. Em toda a obra de Lobo Antunes, nos seus livros, nas suas crónicas, encontram-se, como fogachos, essas primeiras impressões vitais que marcam a singular estética do escritor.

Essa afirmação está em consonância com o que se lê nas crônicas antunianas sobre a infância, em que o tempo, inocentemente marcado a lápis num risco na parede, mostra-nos o olhar do menino para o mundo, olhar que vai subindo e vendo a vida e as pessoas por um ângulo paralelo ao seu universo infantil. E quando dissemos paralelo, é por querer ilustrar o invisível muro que separa o mundo infantil do adulto, desde sempre.

Mas esse universo paralelo desenvolve no menino o olhar poético que é assumido pelo autor, ainda numa das entrevistas com María Luisa Blanco, quando Lobo Antunes discorre sobre a inquietação que o acometeu após as primeiras leituras feitas na infância, e o seu "imenso assombro pelo que se podia fazer com as palavras" e como "a poesia compreendia o autêntico valor das palavras" (ANTUNES, 1998, p. 27-28). Sapato, barriga, joelho... Agora o menino cresceu.

Sim. E aquelas vozes. Normalmente, sento-me e tenho de ficar uma hora à espera, a esvaziar, a esvaziar... Depois vem uma palavra... Começar um capítulo é sempre difícil, o arranque é tão, tão, difícil... E até aquilo que está dentro de nós começar a sair e a andar sozinho.... E só se faz aquilo que o livro quer. Nós vamos atrás do livro, não vale a pena fazer planos, ele foge--nos para todos os lados, não o orientamos, não o dirigimos, vai-se atrás dele. E ele é que diz que acabou. (ANTUNES, 2013, p. 112-122)

O objeto relógio, a patologia "surdez", a lembrança do avô paterno, tudo isso desencadeia uma série de imagens que constituem o imaginário infantil, involuntariamente, pois ao menino se 
justapõem uma série de outras imagens que constituem o cenário de uma época. As lembranças espontâneas repercutem vez por outra nas imagens espalhadas pela duração, pelo tempo. As voluntárias, como as datas de aniversário, morte, enfim, um marco de alguma ocasião, estas voltam a cada data que representam, porque as registramos e nos esforçamos para não esquecê-las, embora, com o tempo, elas acabem se desconfigurando, perdendo o efeito que a princípio causavam. Em Lobo Antunes ficam registrados momentos felizes na casa da infância, a casa que, à criança, parece sempre gigantesca.

Na crônica "Tudo o que cresce precisa de muito tempo para crescer", do seu Quinto Livro de Crónicas, o narrador reflete: "Descobri também que o passado é a coisa mais imprevisível do mundo, não para de se transformar. Lá vem os mortos” (2013, p. 19). Essa reflexão ilustra quase na totalidade o tom nostálgico de quem evoca os mortos, a infância, as tias, tios, avós, pais, o que podemos ver nos fragmentos da crônica "Eu, em agosto":

O mês de agosto passado em casa, a escrever, almoçando e jantando nos restaurantezinhos em torno. [...] Conheço os sem abrigo, as prostitutas, os travestis, os homens que comem sozinhos (tantos homens comem sozinhos, a começar por mim [...]

- Está sempre a olhar para dentro, senhor António

eu que julgava olhar para fora, na minha qualidade de gatuno, porque tenho levado anos a roubar caras, gestos, palavras, coisas de que não me dou conta e me aparecem depois [...] Parece que voltei à minha infância, a Benfica, a Nelas. Não me lembro se era feliz nessa época. Se calhar era. Esqueci, Quer dizer não esqueci as casas nem as travessas: esqueci-me de mim, ou era outro, então. Toda a gente viva nesse tempo. Tardes mais que compridas, infinitas, relógios preguiçosos. Hoje nem mastigam as horas, engolem-nas e o senhor António perde-se nas datas embora as ponha no alto das páginas em que faz o livro. Que livro estás a escrever, senhor António? Não sei. [...] Há qualquer coisa nos adultos que continua a escapar-me. Certos olhares, certas frases. Os suspiros desalentados de uma tia solteira, conseguir espirais de fumo: nunca aprendi. $\mathrm{O}$ meu avô calado: não me recordo de nenhum contentamento nele, recordo-me que lia na varanda para a vinha e é tudo. $\mathrm{O}$ vento nos castanheiros à noite. Um senhor que anunciava ao ir-se embora

- Eu vou chegando

e o mês de agosto passado em casa, a escrever. Se eu conseguisse exprimir, sem ser nos livros, tudo o que tenho dentro, que mundo em chamas não seria, que nortada. Coisas tranquilas também, pequenas doçuras, dedos lentos pelas costas acima. Este inexplicável sentimento de eternidade [...]. Duro cinco minutos: sou eterno. Duro vinte anos: sou eterno. Olha o senhor António que não acaba. (ANTUNES, 2011, p. 201-202).

O excerto nos faz refletir sobre a nossa incapacidade de recuperar a cena vivida em sua imagem tal como aconteceu, a capacidade de guardar a emoção, o enlevo, a duração pura, por reconhecermos o que pensamos e sentirmos a emoção do vivido. Mas isso vai sendo esvanecido, com a sequência de outras vivencias que nos distanciam do momento concreto. Articular essas experiências numa crônica é unir a habilidade do escritor à capacidade de traduzir o tempo da consciência, elástico, múltiplo, numa sequência que traz demasiadas informações e elementos espaciais, dentro de uma retórica poética. É o encontro do passado com o presente em cinco minutos, em vinte anos, em átimos de segundo. É o tempo da duração se impondo sobre o tempo cronológico, o tempo do relógio. 
Mais uma vez Lobo Antunes nos apresenta o que consideramos a poesia na prosa, sob nossa forma de ler e sentir, por ele conseguir expressar algo tão abstrato como a transversalidade do tempo, num apanhado poético capaz de nos fazer pensar nas leis da física, na filosofia, sem deixar de contemplar a poesia. Lembrando Bodei (1997, p. 17),

A "duração" é garantida pela analogia entre a consciência humana e a vida da
natureza no seu conjunto. Ambas são criação contínua, autoprodução. A vida
psíquica é um borbotar constante de nova, imprevisível espontaneidade. [...] Na
Evolução criadora (Bergson, 1907) o acento, mais do que na recuperação do
tempo perdido, incide na projecção para o futuro.

O conflito entre o "ser" que narra está no encadeamento contínuo, na projeção para um futuro, que pode ser inventado, assim como o passado pode ser recriado. Segundo Ricoeur (2017, p. 27), "o problema suscitado entre memória e imaginação é tão antigo quanto a filosofia ocidental”, e para exemplificar ele nos apresenta a distinção entre os modos de apresentação do tema dor em Platão e Aristóteles. Segundo ele, Platão "fala da representação presente de uma coisa ausente; ele advoga implicitamente o envolvimento da problemática da memória pela imaginação". Ou seja, "a representação presente de uma coisa ausente" e Aristóteles "preconiza a inclusão da problemática da imagem na lembrança [...] A memória é do passado" (RICOEUR, 2017, p. 27). No entanto, em Tempo e Narrativa, Ricoeur refuta Aristóteles: "O filósofo pode até negar que o tempo, como tal, é causa desse declínio²: a sabedoria imemorial parece perceber uma conclusão secreta entre "a mudança que se desfaz" - esquecimento, envelhecimento, morte - e "o tempo que simplesmente passa" (RICOEUR, 2010, p. 27).

O tempo simplesmente passa, nos diz Ricouer. Afirmações como essa são recorrentes na obra antuniana, o que nos dificulta escolher um melhor exemplo para melhor ilustrar essa questão, a que melhor acrescenta o lirismo, nos comove e nos acolhe como num poema. Que nos embalam no colo querido da mãe constantemente citada. A mãe jovem, a mãe madura, a mãe velha, a mãe morta. Os passos da duração.

De quem são esses passos? De uma pessoa que morou aqui antes de nós, de ti, de mim que não paro quieto para diante e para trás no corredor, à procura de não sei quê, a tentar desembaraçar-me de não sei quê, a pensar em não sei quê, com medo? [...] Se eu pudesse levantar-me da cama, vestir roupão, ir ver. Olha, apareceu-me agora isto de repente, será a morte?

Os passos, metáfora do tempo, do relógio, da barriga, dos mortos, dos fantasmas que passeiam pela casa. O travesseiro solitário, ao lado, que não responde de quem são esses passos. Todas as lembranças a caminhar para algo que se chama velhice (futuro?) e que trará a morte, mas e as sensações, lembranças e recordações? Tudo acontece ao mesmo tempo, a se multiplicar desde quando o menino via os sapatos por baixo da mesa, depois começou a ver os joelhos, por fim,

\footnotetext{
${ }^{2}$ Em referencia a uma reflexão de Aristóteles sobre as questões referentes a como as coisas se desfazem.
} 
começou a ver as barrigas, e com elas, as pessoas e ele, e o que delas pensava. O Antoninho está lá, a espiar e o Sr. António, a temer os fantasmas.

\section{REFERÊNCIAS}

ANTUNES, A. L. Livro de crónicas. Lisboa: Publicações Dom Quixote, 1998.

ANTUNES, A. L. Segundo Livro de Crónicas. Lisboa: Publicações Dom Quixote, 2002

ANTUNES, A. L. Terceiro Livro de Crónicas. Lisboa: Publicações Dom Quixote, 2005

ANTUNES, A. L. Quarto Livro de Crónicas. Lisboa: Publicações Dom Quixote, 2011

ANTUNES, A. L. Quinto livro de crónicas. Lisboa: Publicações Dom Quixote, 2013

ANTUNES, A. L. Entrevista com Lobo Antunes. VIS ÃO, n. 1085, p. 112-122, 19 a 25 de dezembro de 2013

BLANCO, M. L. Conversas com Lobo Antunes. Lisboa: Dom Quixote, 2002.

BAUDELAIRE, C. Petits poèmes en prose (Le Spleen de Pais), 1996

RICOEUR, P. Tempo e narrativa. Volumes 1, 2 e 3. São Paulo: Martins Fontes, 2010.

RICOEUR, P. A memória, a história, o esquecimento. Campinas: Unicamp, 2017. 